\title{
Processo PTA-P - Uma Revisão da Literatura como Base para Inovações. Parte 1 de 2: Elementos Construtivos
}

\author{
(PTA-P Process - A Literature Review as Basis for Innovations. Part 1 of 2: Constructive Elements)
}

\author{
Régis Henrique Gonçalves e Silval, Jair Carlos Dutra ${ }^{1}$, \\ ${ }^{1}$ UFSC Departamento de Engenharia Mecânica / LABSOLDA - Instituto de Soldagem e Mecatrônica, Florianópolis, SC, Brasil, \\ regis@labsolda.ufsc.br
}

\begin{abstract}
Resumo
Em vários setores industriais estão presentes mecanismos de desgaste da superficial. Exemplos onde se observa grande impacto desse fator são as áreas de geração de energia, produção e refino de petróleo e mineração, que se caracterizam por processamento contínuo em larga escala. Como solução para este problema, são possíveis duas abordagens: o revestimento prévio das superfícies com materiais de alta resistência e a manutenção periódica. Uma opção para este procedimento é a soldagem PTA-P (Plasma com adição de pó metálico). Inserida no contexto de um projeto dedicado à Pesquisa e Desenvolvimento do processo PTA-P para geração de inovações do sistema e sua parametrização, a ampla Revisão da Literatura que se inicia neste artigo e se estende por mais um procurou incorporar não somente fatores científicos, mas também tecnológicos, com especial atenção a linhas de pesquisa atuais em centros de referência mundial. Apesar de o processo ter suas bases estabelecidas, foram verificados diferentes princípios construtivos, aplicações, vantagens e limitações. Ao longo da série, estas informações são confrontadas entre si e com conhecimento próprio gerado, de maneira crítica e sob critérios concretos. Neste primeiro artigo, são abordados aspectos históricos e conceituais e diferentes projetos de elementos construtivos fundamentais do processo, que incorrem em diferentes faixas de operação e aplicações alvo.
\end{abstract}

Palavras-chave: Soldagem Plasma Pó; Revestimento; Tocha; Alimentador de Pó.

Abstract: Wear mechanisms are present in several industrial sectors and affect pieces, equipments, reservoirs and pipelines surfaces. Examples where this can be noticed are energy generation, oil production and refining and mining, characterized by large scale continuous processing. Two approaches are possible as solutions for this problem: previous surface coating with high resistance materials and periodic maintenance. An option for this procedure is PTA-P Welding (Plasma Transferred Arc with Powder as filler material. In the framework of a $R \& D$ project dedicated to innovations regarding PTA-P equipment and parameterization, this two part article series provides a wide Literature Review concerning not only scientific, but also technological aspects, with special attention given to current research lines of world reference center. Despite being well established in its basic principles, a profusion of different constructive features, applications, advantages and limitations of the PTA-P could be observed. Along this series this information will be confronted mutually and with in-house generated knowledge in critical approach, under concrete criteria. This first article deals with historical and conceptual aspects and different projects of fundamental system constructive elements, giving rise to different operation ranges and target applications.

Keywords: Plasma Powder Welding; Coating; Torch; Powder Feeder.

\section{Introdução}

O rápido desenvolvimento econômico mundial demanda continuamente maiores quantidades e taxas de produção. A conseqüente mecanização dos processos resulta em solicitações mecânicas de maior intensidade ou em maior escala devido ao contato dinâmico das partes dos equipamentos ou destas com o substrato sendo processado ou transportado. Em dependência da natureza dos elementos envolvidos, ataques químicos podem atuar de maneira exclusiva ou em conjunto com as solicitações mecânicas, contribuindo para o desgaste das superfícies das peças. Para que se mantenham estáveis as condições de produção, este fato leva à necessidade irrevogável de se a realizar manutenção

(Recebido em 14/02/2012; Texto final em 01/03/2012). ou a troca das peças desgastadas, o que acarreta em custos de materiais em si e decorrentes de paradas como serviços de terceiros, aluguel de equipamentos, etc., ou de pré-revestimento das peças. Em alguns casos, a troca da peça é economicamente inviável, como em pás de turbinas de geradores em hidrelétricas. Além disso, as próprias características intrínsecas dos materiais resistentes podem inviabilizar tecnicamente a fabricação de peças completas devido à impossibilidade ou extrema dificuldade e alto custo de processamento em determinados casos.

Dentro desta problemática, a solução encontrada é o revestimento com material resistente às solicitações causadoras de desgaste. Este revestimento pode ser realizado de maneira preventiva ou corretiva. Desta maneira, as peças podem ser fabricadas com ligas metálicas de menor custo e mais facilmente trabalháveis, ficando as ligas resistentes de alto custo presentes somente nas posições onde as suas propriedades são de fato necessárias. 
Fatores econômicos e técnicos, como determinam o tipo de revestimento a ser aplicado quanto ao processo e material a ser aportado. Estão disponíveis comercialmente diversas opções, desde processos manuais de baixa produtividade até processos automatizados, com equipamentos de alta produtividade e alto custo.

Para determinadas aplicações nos setores industriais, alguns processos de revestimento são excluídos prontamente por não atingirem especificações requisitadas e outros são suplantados pelas vantagens atingíveis pelo processo PTA-P (Plasma com adição de pó). Primeiramente, este é um processo de soldagem, resultando, portanto, em uma união metalúrgica entre a as camadas depositadas e o substrato e entre as camadas seqüenciais. Pelo contrário, a Aspersão Térmica, utilizada também para revestimentos metálicos, apresenta união por agarramento mecânico do material depositado na rugosidade superficial do substrato, o que a inabilita para certas aplicações.

As propriedades vantajosas creditadas ao PTA-P formam uma rede onde umas influem nas outras, culminando em benefícios produtivos com potencial para impactos sensíveis na economia de empresas usuárias.

O trabalho descrito na série de artigos que se inicia com o presente objetivou alcançar conhecimentos científicos e tecnológicos sobre o processo PTA-P, no intuito de direcionar o projeto dos componentes do sistema e a formulação de procedimentos de soldagem de maneira a obter as vantagens ora citadas em revestimentos metálicos, incluindo aplicações fora da posição plana, raramente mencionadas na literatura ou observadas industrialmente. Neste primeiro artigo se fornece um panorama sobre as características do processo, incluindo um breve histórico, princípio de funcionamento e diferentes projetos de elementos construtivos fundamentais do processo, que fornecerão ao leitor um adequado embasamento para as publicações que se seguirão.

\section{Breve Histórico e Conceitualização do processo PTA-P}

O surgimento do Processo Plasma de Arco Transferido Alimentado com Pó (PTA-P) é colocado sob óticas diversas por diferentes autores. Apesar disso, existe certa congruência quanto à época na qual houve a apresentação pública do processo (início da década de 60 [1-9]) e ao seu criador, a Union Carbide Co. $[2,4,7]$. Mais precisamente, a citada empresa demonstrou o processo na $42^{\mathrm{a}}$ Reunião Anual da AWS, o qual foi patenteado em 03/11/1961, sob a denominação "Procedimento e Aparato para Aporte de Pó Metálico, Depositado e Soldado com Plasma de Arco Transferido" [7]. Porém, segundo Sun e Huang [10], a criação do processo remete à década de 50 e apenas o início de sua comercialização aos anos 60 . É provável que essa fonte tenha se baseado na primeira patente de tocha Plasma, de 1953 [8]. Já no Japão foi a empresa Daido Steel quem obteve a patente do processo PTA, em 1973, denominado por esta companhia de Plasma Powder Welding, PPW [4]. Como primeiras aplicações, se faz alusão a revestimentos soldados de alta qualidade na indústria nuclear [1].

A partir de então o processo se difundiu. A designação mais disseminada é PTA (Plasma Transferred Arc - plasma de arco transferido), provavelmente advinda de uma abreviação não criteriosa da denominação supracitada "Procedimento e Aparato para Aporte de Pó Metálico, Depositado e Soldado com Plasma de Arco Transferido". No entanto, os autores do presente trabalho adotaram a denominação PTA-P. A razão para isto reside em uma tentativa de melhor distinguir o processo de seu similar, o PAW (Plasma Arc Welding), visto que este, na maioria absoluta de suas aplicações, este também opera com arco transferido. Ou seja, o nome PTA (Plasma Transferred Arc) não promove, absolutamente, distinção entre o processo conhecido como tal e o PAW, com ou sem material de adição. Esta distinção deve ocorrer, pois, apesar da similaridade construtiva dos processos PAW e PTA-P, suas aplicações e parametrização são deveras diferentes. O principal aspecto a ser lembrado é próprio resultado esperado de cada um: o PAW surgiu como evolução do TIG exatamente para fornecer maior constrição do arco e, com isso, maior penetração, chegando até a aplicações de keyhole. No PTA-P, as aplicações são fundamentalmente de revestimento, nas quais baixa diluição (e baixa penetração) é buscada e, em assim sendo, sua parametrização, conjuntamente com o formato do metal de adição, convergem no sentido de potencializar estes resultados esperados. Corrobora esta iniciativa de revisão da conceitualização do processo o fato de que o nome PTA não se encontra normatizado. Além disso, a norma DIN adota nomenclatura distinta, ressaltando o fato de que o material de adição é em pó e que o processo é para revestimento: Plasma Pulver Auftragschweissen - Soldagem de Revestimento por Plasma e Pó (segundo Dolles [11], o processo Plasma-Pulver-Auftragschweissen se encontra na classificação de Revestimento, subclassificação Revestimento do Estado Líquido ou Pastoso, da norma DIN 8580). Outrossim, variações de nomenclatura são encontradas na literatura, as quais também designam melhor o processo do que simplesmente PTA: PPW (Plasma Powder Welding) [4], Powder Plasma Hardfacing [12], Powder Plasma Arc Welding [2, 13 (PPAW)], Plasma Pulver-Auftragschweissen [14, 15] Plasma weld surfacing [16], Plasma Arc Powder Surfacing [16, 17], Plasma Transferred Arc wearfacing / hardfacing / wear surfacing [18].

\section{Componentes de um Sistema PTA-P}

O processo PTA-P se permite explicar por suas partes constituintes. A fonte calorífica utilizada no processo é um plasma térmico, que assume um perfil de temperaturas consideravelmente altas, para o qual se atribuem diferentes valores de temperatura média, por exemplo, aprox. $16700^{\circ} \mathrm{C}$ $[18,19]$.

Para controlar essa energia, adequando-a ao processo PTA-P, é necessária uma fonte de corrente para o arco principal e uma fonte de corrente para o arco piloto ou arco não transferido, com ignitor de alta frequiência para sua ignição e uma tocha de soldagem refrigerada. Para viabilizar a adição de material, é necessário um aparato para armazenagem e alimentação do pó, além dos gases do processo e seus respectivos reguladores ou controladores. A Figura 1 ilustra os componentes do sistema. 


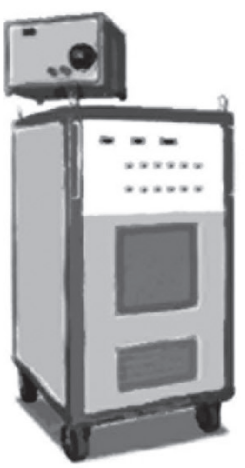

$\begin{array}{cc}\begin{array}{l}\text { Fonte de energia } \\ \text { do arco principal }\end{array} & \text { arco piloto - arco } \\ & \text { não transferido }\end{array}$

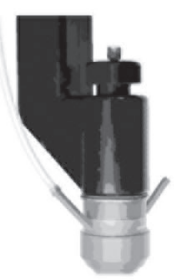

Tocha de Soldagem

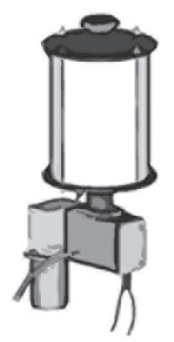

Alimentador de Pó - ADP

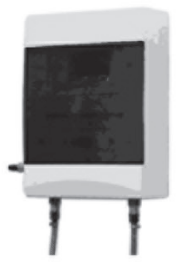

Válvulas
controladoras de gás

Figura 1. Esquema de um equipamento para soldagem PTA-P

\subsection{Tocha}

Devido à variedade de aplicações industriais do plasma, não há um desenho universal de tocha que atenda aos os requisitos de todas ao mesmo tempo. Uma tocha plasma industrial é um aparato eletroquímico e térmico capaz de transformar energia elétrica em energia térmica [3]. Segundo Marconi [7], são citadas perdas máximas de cerca de $20 \%$ para o sistema de refrigeração, e que a finalidade essencial do projeto da tocha é produzir um arco estável e perfeitamente centralizado.

Os fundamentos construtivos das tochas PTA-P devem, portanto satisfazer os requisitos que tornem a aplicação industrial do processo técnica e economicamente viável e competitiva. Neste âmbito, injeção de pó ao arco é uma dos desafios do PTA-P. A distribuição das partículas coaxialmente ao arco, ou através de orifícios concêntricos ao arco, em um ângulo determinado, resulta em limitação da granulometria utilizável e reduz a robustez do processo, segundo Dilthey e Kabatnik [14]. É válido ter em mente que esta afirmação está contida num trabalho que fomenta outra forma de injeção do pó, através do eixo central da tocha.

O tipo de injeção afeta a forma do arco. Em alguns trabalhos [8, 20,21], é sugerido que o arco é cilíndrico. Diaz [22] relata que o arco, originalmente cilíndrico, passa a ter forma de um cone truncado, quando os jatos de gás de arraste se convergem antes da peça. Além disso, Hongying [12] introduz o conceito de ponto focal da injeção de pó, que é a localização na qual diversos jatos de injeção de material se interseccionam, sob o bico constritor, independentemente do tipo de tocha. Quanto a essa característica, as tochas podem ser classificadas em três tipos: injeção externa, injeção interna e injeção central de pó.

A injeção externa de pó é a mais difundida comercialmente. Ela se caracteriza pelo fato de os orifícios injetores se encontrarem na superfície inferior do bico constritor. Dessa maneira, o material aportado viaja por determinado tempo fora do arco até adentrar o mesmo. O ponto focal será determinado pelo ângulo dos orifícios injetores em relação ao eixo do arco elétrico e pela distância dos primeiros ao segundo.
$\mathrm{Na}$ injeção externa de pó Deuis [1] sugere duas variações quanto ao ponto focal, que é ponto de cruzamento dos jatos de pó na coluna do arco. O trabalho trata de deposição de partículas duras (carbonetos, cerâmicas) em matriz metálica. A primeira versão prevê um projeto de tocha (ângulo de injeção) no qual o ponto focal do pó fica acima da poça de fusão, a cerca de meia distância do bico constritor. Ela é chamada co-deposição, pois há alimentação conjunta de partículas duras e pó da matriz metálica. Para o caso de injeção de partículas, somente as partículas duras são alimentadas e a matriz metálica é o próprio substrato. Nesta variação a tocha é projetada e posicionada de modo a focalizar o pó na superfície do substrato.

Na mesma linha de raciocínio, é apresentada a patente [23] de um método de soldagem PTA-P, o qual nada mais é do que uma combinação geométrica entre o ângulo dos canais de injeção em relação ao eixo da tocha e a DBP (Distância Bico constritor - Peça), de maneira que o ponto focal posicionado acima da peça é recomendado para aplicações de revestimento e sobre a poça, para união. O princípio, além de talvez não representar uma inovação tecnológica que justifique uma patente, vai de encontro ao exemplo de aplicação descrito por Marconi e Marconi [2], em união de topo de tubos de parede espessa, no qual se utilizou injeção interna, com ponto focal inerentemente acima da superfície da peça.

Díaz [22] também investigou o ângulo dos canais injetores, mas em relação à superfície inferior do bico constritor (Figura 2). Um ângulo de $30^{\circ}$ resultou em partículas não fundidas $\mathrm{e}$ falta de fusão nas laterais do cordão, o que não ocorreu para $60^{\circ}$. No último caso, o gás de arraste incide diretamente sobre a poça (maior distância focal, igualada à DBP), deslocando-a para as laterais e causando melhor fusão nestes pontos. O autor menciona resfriamento da poça pelo gás de arraste, o que, neste caso, contribuiria para maior penetração nas laterais do cordão. Outra hipótese seria a maior densidade de corrente nas laterais, causando também maior convecção, pois de fato há um achatamento do arco na direção transversal. 


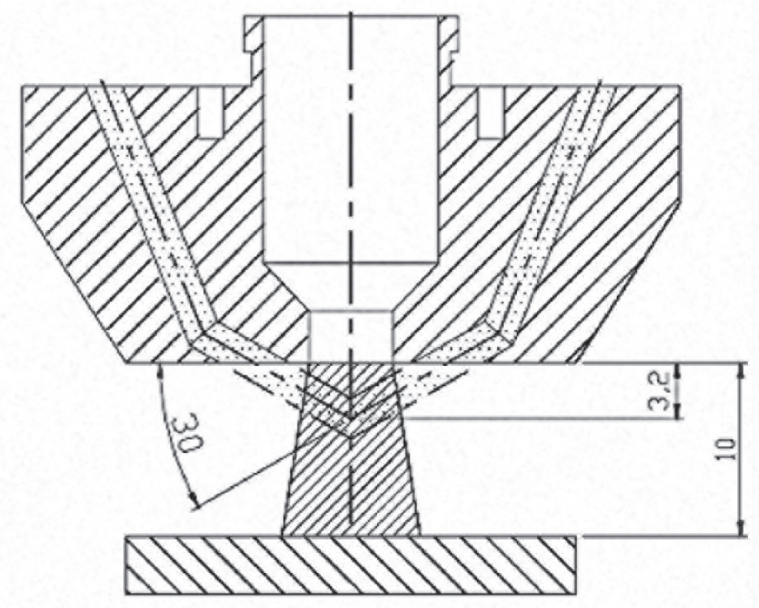

Bico $30^{\circ}$

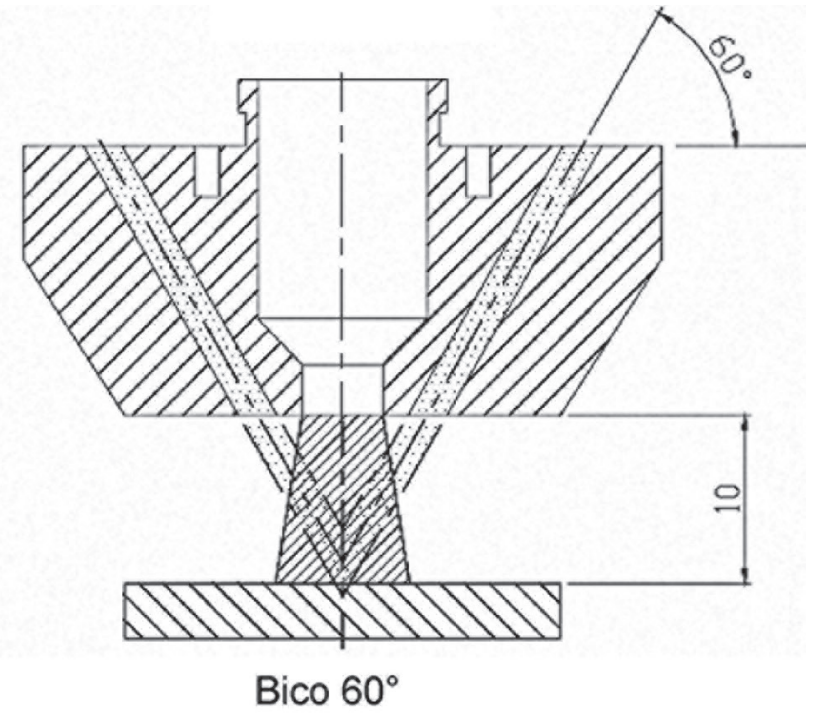

Figura 2. Efeito do ângulo dos canais de injeção de pó do bico constritor em relação à trajetória das partículas e do gás de arraste (adaptado de [22])

No mesmo trabalho foi verificado que o ângulo de $60^{\circ}$, propicia menor espessura da ZTA, apesar da maior penetração. Uma razão para isso poderia ser um maior valor de tensão do arco para $30^{\circ}$. Mas a diferença de tensão entre os dois ângulos não se mostrou significativa (cerca de $0,5 \mathrm{~V}$ para condições normais de deposição). Uma hipótese plausível, portanto, seria o fato de que o pó incidente na poça pelos canais de $60^{\circ}$ apresentam menor temperatura e, assim retira mais calor da poça de fusão. Já no caso do ângulo de $30^{\circ}$, as partículas permanecem mais tempo no arco e chegam à poça mais quentes.

As desvantagens atribuídas à injeção externa são:

- As partículas entram no arco fora da tocha, com ponto focal abaixo do bico constritor, o que diminui o tempo delas no plasma, e causa não fusão ou fusão insuficiente das maiores ou daquelas com ponto de fusão elevado. A conseqüente maior demanda de energia de soldagem resulta em maior diluição $[14,24]$. Ribeiro [25], utilizando uma tocha deste tipo, necessitou aumentar a energia de soldagem para minimizar a presença de partículas não fundidas no depósito;

- O gás de arraste não poderia ser utilizado ativamente para alterar a eficiência do processo, pois tem baixa influência na pressão do arco e sua constrição [14];

- Maior desperdício de pó [24];

- Perturbações nos canais individuais de pó podem causar desvio do arco e inconsistências no depósito [14, 24].

Como vantagens, os mesmo trabalhos citam alta taxa de fusão (para grãos de até $100 \mu \mathrm{m}$ ) e baixo desgaste da tocha [20], maior simplicidade e confiabilidade em termos de evitar contaminação dos canais [24].

Há variações quanto ao número de orifícios injetores nos modelos comerciais. No caso de dois, Diaz [22] estudou a influência do posicionamento dos orifícios em relação ao deslocamento da pistola. Chegou à conclusão que o posicionamento longitudinal dos orifícios injetores em relação ao cordão apresenta melhor acabamento, acredita-se que devido à menor sensibilidade a variações nas vazões de pó e de gás de arraste, e adota esta configuração para o restante do trabalho, apesar de penetração não uniforme.

Aplicações com apenas um orifício também foram realizados em alguns trabalhos [10, 22, 26-29], assim como também seis orifícios [11]. A alimentação concêntrica, com número maior de canais injetores, confere ao arco certa independência da direção de solda. De fato, para o caso de operações manuais sobre peças de geometria heterogênea e de grandes dimensões, esta característica é interessante, pois o soldador tende a alterar o posicionamento relativo tocha / peça, mesmo em pequena escala, ao longo do curso da solda.

Uma variação de tocha com injeção externa foi utilizada por White e Solomon [30,31] para soldas submarinas molhadas, com uma câmara de exclusão de água.

Outra versão implementou um raio de curvatura nos canais de injeção e melhorias na fabricação, obtendo menor rugosidade interna. Estas iniciativas de Draugelates, Bouaifi e Schultze [32] objetivaram melhores condições de injeção do pó e menor desgaste das paredes dos canais, em altas vazões de pó, de 12 $\mathrm{kg} / \mathrm{h}$ a $15 \mathrm{~kg} / \mathrm{h}$.

O projeto do circuito de refrigeração da tocha é importante, no tocante à reducao nas dimensões da tocha, na manutenção de uma satisfatória capacidade de corrente, maior tempo de vida dos componentes e na conservação das propriedades superficiais dos canais de injeção de pó [33].

A injeção interna é realizada através de um jato anular, coaxial ao arco [14, 24, 34]. O projeto deste tipo de tocha prevê, portanto, além do bico constritor e bocal do gás de proteção, também o bocal focalizador [24]. São encontradas aplicações deste tipo de tocha em diferentes publicações [2, 4, 5, 7]. Neste caso, o pó é alimentado diretamente na região mais quente do plasma e é acelerado à peça por ele [24]. Portanto, partículas maiores que as permitidas para injeção externa são fundidas (até $200 \mu \mathrm{m}$ ) [14, 15, 34]. Os fluxos do gás de plasma e do gás de arraste se encontram ainda dentro da tocha. Desta forma, a manipulação da vazão de ambos em conjunto ou separadamente 
pode ser utilizada para atuar na eficiência térmica do processo e na diluição, segundo Dilthey e Kabatnik [14]. Uma tocha com alimentação interna é mostrada esquematicamente na Figura 3.

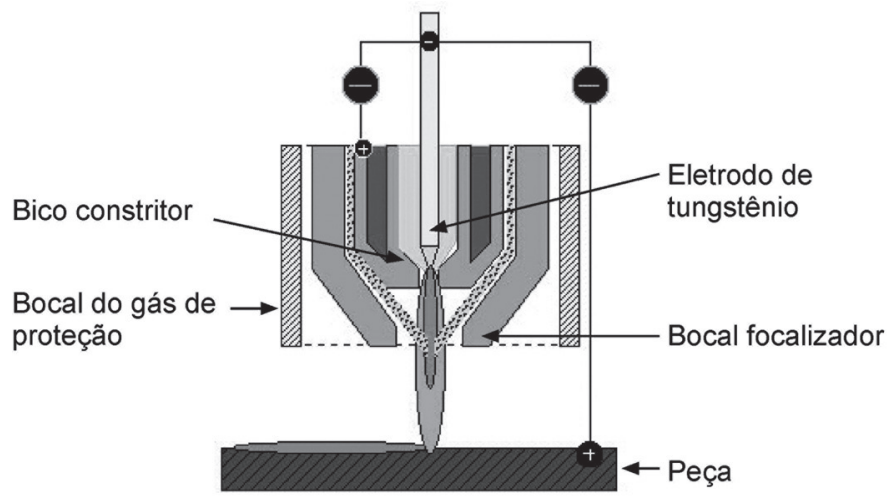

Figura 3. Tocha PTA-P com injeção interna de pó (adaptado de [7])

Pavlenko [34], considerando uma tocha com alimentação interna, simulou o movimento das partículas e seu aquecimento a partir de sua imersão no arco. Neste ponto se faz alusão aos seus resultados quanto à trajetória das partículas, que é afetada grandemente pelo projeto da tocha. Como mostra a Figura 4, partículas maiores sofrem menor influência do jato axial do plasma em sua trajetória desde o ponto de injeção até a peça. Ou seja, essas partículas tendem mais a manter seu movimento no ângulo de injeção. Para ângulos maiores, (p. ex. $70^{\circ}$, na figura), partículas tendem a atravessar o arco e colidir com a peça fora da poça, ou mesmo, no caso desse tipo de tocha, colidir com a parede interna do bocal focalizador e formar uma gota de grandes dimensões, entupindo o canal [3]. Dessa maneira, ângulos mais agudos seriam mais recomendados, principalmente para maiores granulometrias da liga aportada.

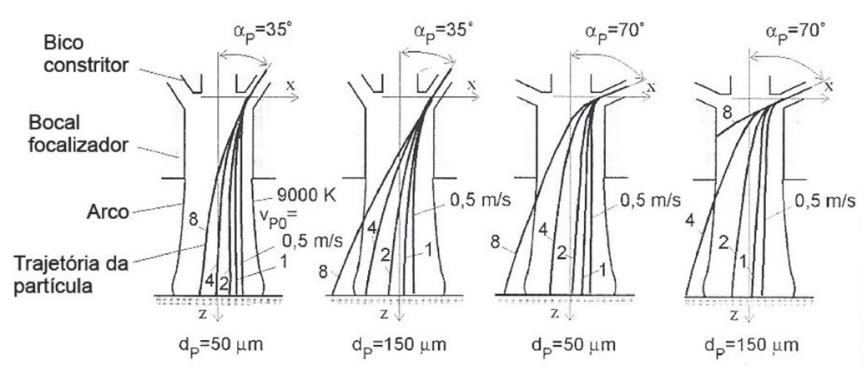

Figura 4. Trajetória das partículas $\left(\mathrm{Vp}_{0}=\right.$ velocidade das partículas no ponto de injeção) (adaptado de [34])

Colisões nos canais de pó internos à tocha causam irregularidades nas trajetórias das partículas, segundo Fauchais e Vardelle [3] e abrasão dos canais, principalmente no caso de partículas de elevada dureza [14]. O sistema de injeção central de pó possibilita a solução de tais problemas [14]. Este trabalho atribui também maior taxa de fusão e faixa granulométrica (até $300 \mu \mathrm{m})$ passível de ser adequadamente fundida. A Figura 5 mostra em corte o conceito da tocha para injeção central de pó. Ao invés de um eletrodo cilíndrico de tungstênio, se observa um tubo de cobre com uma ponteira tubular de tungstênio brasada em sua ponta, através do qual o pó flui. O gás chamado adicional é utilizado para direcionamento do fluxo assim que o fluido pó/ gás de plasma sai do eletrodo tubular [14].

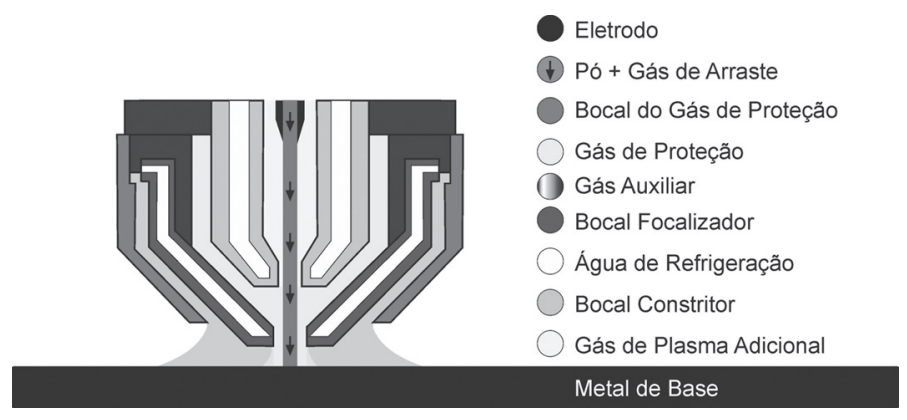

Figura 5. Tocha PTA-P com injeção central de pó (adaptado de [14])

Som [24] cita que ainda não havia aplicação prática para esta tocha (à época da publicação) e um dos problemas é a alta complexidade de construção da tocha. De fato, em ensaios práticos de Dilthey e Kabatnik [14] surgiram dificuldades no processo em relação a sensibilidade de sua estabilidade. A vantagem buscada foi alcançada, sob as condições restritas, pois pós de granulometrias entre $300 \mu \mathrm{m}$ e $355 \mu \mathrm{m}$ puderam ser soldadas.

Além dos tipos de injeção de pó citados, são citadas versões na qual o pó é transportado juntamente ao gás de proteção [35, 36]. As vantagens enumeradas por Sidorov [35] são: menor consumo de gás, pois não se utilizam os outros fluxos para transportar o pó; proteção mais eficiente, pois o pó em suspensão no gás de proteção age como um filtro poroso (tipo gas lens), tornando o fluxo rígido, homogêneo e laminar; menor tendência ao entupimento na saída do pó e menor tamanho da tocha. Os dois últimos fatores, de acordo com experiência do LABSOLDA em comparação com injeção interna, podem ser consistentes. Porém, se observa possibilidade de limitação da capacidade de fusão do pó e alto desperdício por partículas não fundidas. As desvantagens das outras versões, como maior consumo de gás, maior numero de bocais, maior número de linhas de gás, entupimento, menor eficácia do gás de proteção, mencionadas por Sidorov [35], podem ser solucionadas via parâmetros do processo.

Füssel [6] e Schnick [37] lançaram mão de modelamento e simulação do arco elétrico e tocha de soldagem para fins de projeto da mesma. De fato, o desenvolvimento de tochas por protótipos tem alto custo, há pouco ganho em conhecimento [6] e os novos sistemas de simulação evoluíram em operação, interatividade com modelos de diversos fenômenos presentes (escoamento multifásico, turbulência, radiação) e estabilidade [37]. Além disso, medições na região do arco são complexas [6]. A Figura 6 mostra uma simulação realizada para definir o design mais apropriado de bocal de gás de proteção na soldagem PTA-P. Segundo os desenvolvedores, o resultado foi aplicado na prática. 


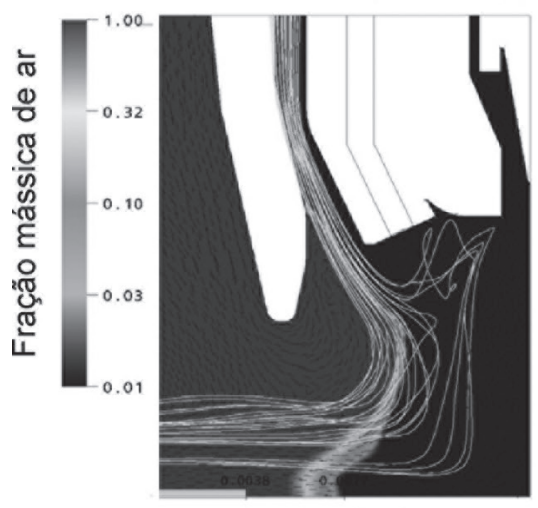

Versão 1

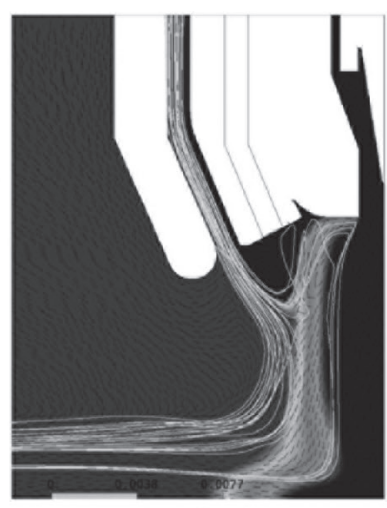

Versão 2

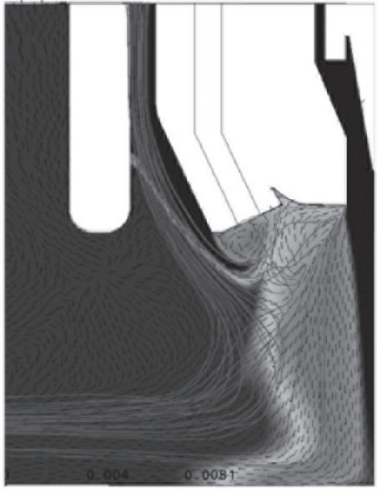

Versão 3

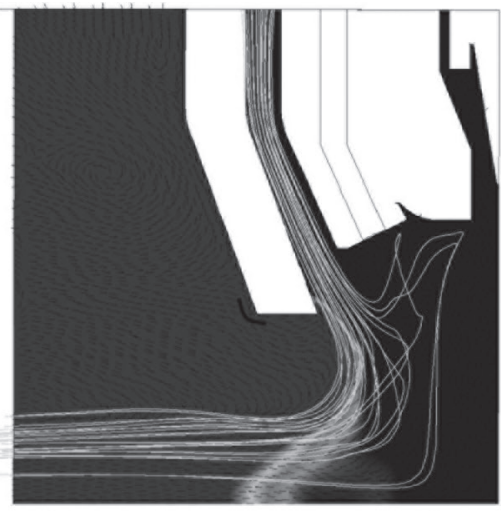

Versão adotada na produção

Figura 6. Simulação dos fluxos dos gases, para definição de uma geometria do bocal de proteção com eficiência otimizada (adaptado de [38])

\subsection{Alimentador de Pó (ADP)}

O alimentador de pó (designado no presente texto por ADP) é um componente fundamental nos equipamentos para o processo PTA-P. Ele é responsável pela dosagem da liga metálica em pó a ser injetada no arco, através da tocha de soldagem e seu comportamento determina o grau de homogeneidade e repetitividade da alimentação de pó e, conseqüentemente, é fator de importância para a qualidade da solda. Apesar de existirem no mercado vários princípios construtivos disponíveis, a literatura especializada em soldagem não aborda as características dos modelos usados nas pesquisas. As descrições fornecidas limitam-se a algumas constantes como o fato de a maioria dos equipamentos terem o ADP acima da tocha, sendo a maioria das aplicações na posição plana, e especificações quanto à forma e granulometria requeridas, sem citar o princípio de funcionamento.

Gomide [39] estratifica os transportadores de sólidos encontrados industrialmente em dois tipos gerais: volumétricos e gravimétricos. Os dispositivos volumétricos trabalham com uma vazão em volume constante, enquanto os gravimétricos, de construção mais complicada, mantém a vazão mássica constante. No caso do PTA-P são utilizados os dispositivos volumétricos para a dosagem. Como exemplos desse tipo, existem os transportadores helicoidais, ou fusos transportadores, válvulas rotativas, mesa dosadora e válvulas gaveta.

As dificuldades encontradas na alimentação de pó são sua compactação, segregação de partículas mais densas (pós não pré ligados ou pseudo-ligas) e baixa escoabilidade. Huang et al. [40] utilizaram um ADP com dispositivo de vibração provavelmente para sanar tais problemas. A representação esquemática do sistema feita por Milligan e Narasimhan [41] mostra o silo do ADP sendo pressurizado e ausência de gás de arraste. De fato, alguns autores relatam também vazões de gás de arraste relativamente baixas. Isso provavelmente está atrelado ao fato de que os ADPs estão posicionados acima do nível da tocha e a solda é na posição plana, ou seja, a gravidade age a favor da injeção do pó. O modelo comercial aplicado por Marconi e Marconi [2], do tipo válvula rotativa, possui sistema de aquecimento do silo para evitar a umidificação / desumidificar o pó (sem mencionar isto também teria efeito na taxa de fusão, por pré-aquecimento do pó).

Dolles [11] usou um ADP comercial, do tipo mesa dosadora modificado. O modelo pode ser visto na Figura 7. O mesmo tipo de ADP é divulgado por Glynn [42].

Nota-se, na Figura 7, o agitador central, que visa evitar segregação e compactação do pó [11, 42]. Neste caso, a dosagem de pó é realizada pela utilização de diferentes geometrias de discos e pela regulagem da sua rotação. Desvantagens deste tipo são a complexidade construtiva e dificuldade de desmontagem para limpeza.

O ADP do tipo fuso é o mais presente na literatura. Em artigos e bancos de dados de patentes são encontradas diversas variações [22, 28, 40, 43, 44]. Neles um fuso é acionado por
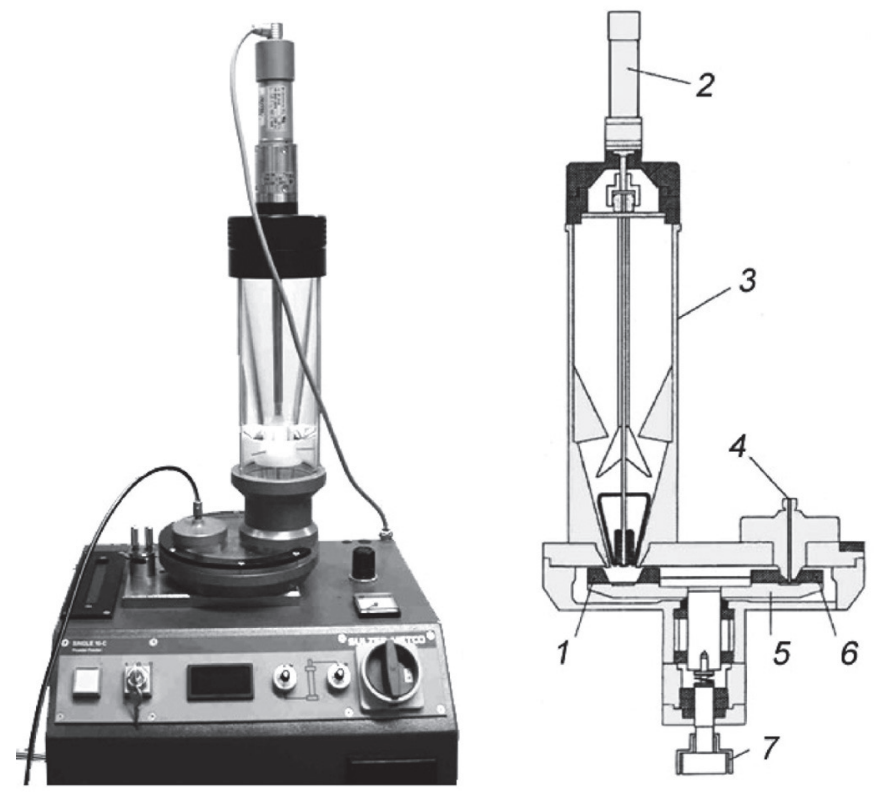

Figura 7. ADP tipo mesa dosadora modificado por Dolles [11] (1- coleta de pó pelo disco; 2- motor para o agitador; 3-silo armazenador; 4- flange para mangueira de saída de pó; 5disco; 6- sucção do pó; 7- motor da mesa giratória) (adaptado de [11]) 

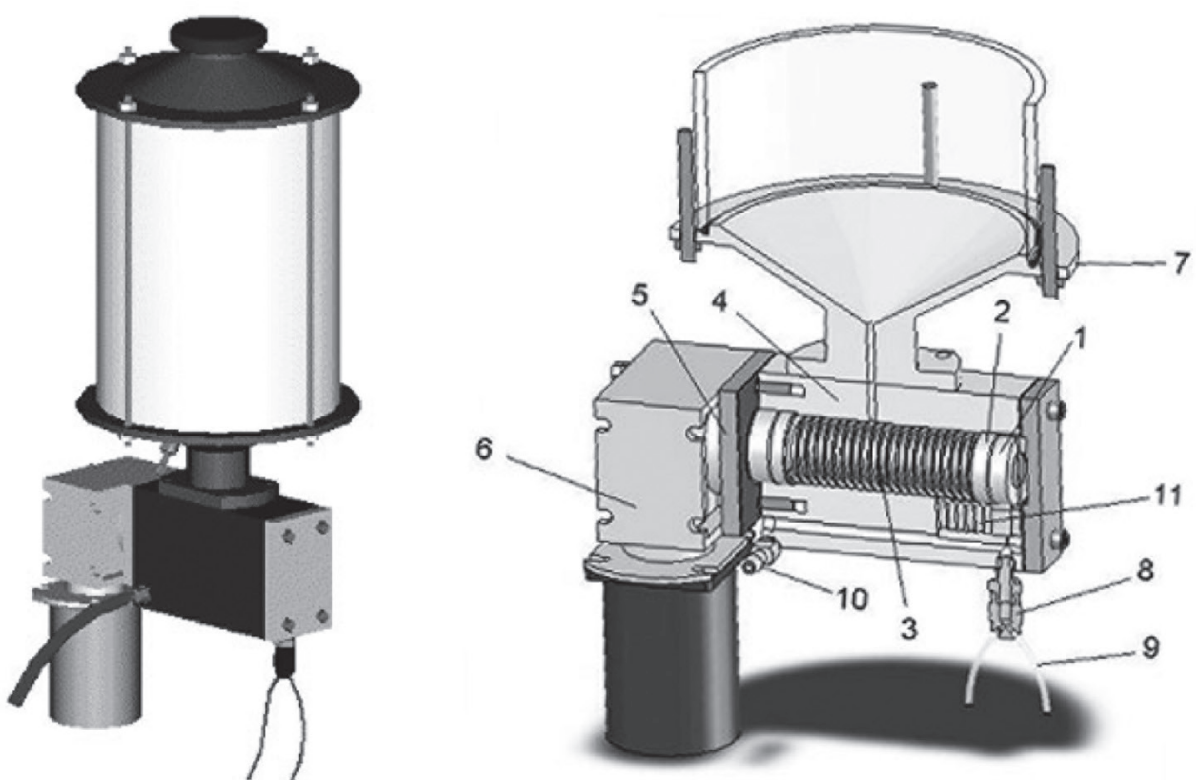

1 - Vedação

2 - Rolamento

3 - Fuso transportador

4 - Corpo

5 - Tampa

6 - Motor

7 - Base reservatório

8 - Divisor

9 - Mangueiras flexíveis

10 - Entrada gás de arraste

11 - Distribuidor

Figura 8. Modelo em CAD do ADP desenvolvido por Díaz [22] (adaptado de [22])
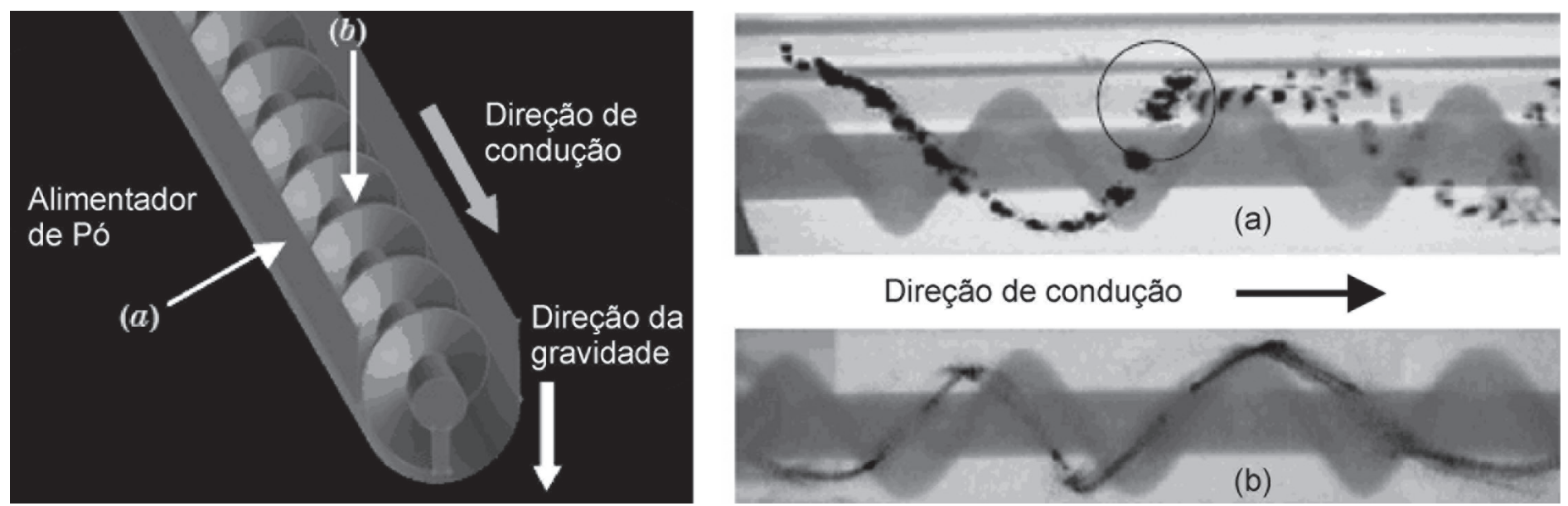

Figura 9. Representação esquemática das direções de irradiação do fuso e imagens do movimento das partículas rastreadas, feitas a partir de sobreposição das radiografias (adaptado de [47])

um motor, deslocando um volume de pó até a queda na linha de transporte. A rotação é, portanto, responsável pela vazão do pó. Existe um gás que pressuriza o silo, que tem a mesma origem do gás que arrasta o pó.

O mesmo tipo é utilizado por Hallen em [28]. Nesta variação, no entanto, o pó cai sobre o fuso através de um orifício que liga este ao silo. Essa versão baseou o desenvolvimento de Díaz [22], Figura 8.

Em ensaios detalhados, este modelo foi submetido à análise de desempenho sob diferentes condições [45]. Foram constatadas ausência de repetitividade e influências significativas da quantidade de pó no silo sobre a taxa de alimentação. Mesmo esses erros não se mostraram tampouco sistemáticos. É interessante mencionar que Ribeiro [25] também relata irregularidades na alimentação de pó com o princípio de fuso.

Stand e Streicher [44] registraram patente de um ADP do tipo fuso, com uma câmara posterior, na qual o pó é fluidizado.
Esta fonte menciona pela primeira vez, em aplicações de alimentação de ligas em pó para revestimento, o conceito de Fluidização, para carrear o pó à tocha.

Os problemas atrelados ao transportador tipo fuso são a rotação do pó junto ao fuso, sem que este seja efetivamente alimentado à frente, chamado "blinding", o surgimento de efeitos cíclicos, que tornam a alimentação heterogênea e a compactação, e conseqüente entupimento no caso de pós muito finos, segundo Steen [43]. Spivakovsky [46] cita ainda desgaste do sistema e alto consumo de potência, devido ao atrito entre pó e o fuso e as paredes internas, e trituramento do material. Como Huang [40], Steen [43] sugere vibração do componente para evitar o entupimento nos canais de alimentação. Numa investigação mais aprofundada, o movimento do pó transportado por um fuso foi observado via Raios X [47]. Os autores afirmam que há escorregamento de pó sobre os filetes, o que juntamente à turbulências nas bordas dos filetes, resulta numa velocidade 
média do pó três vezes menor que a do fuso na direção de transmissão. A Figura 9 ilustra o movimento das partículas via manipulação visual das radiografias. Nota-se, a perturbação da velocidade quando o pó passa pelas bordas dos filetes, por cisalhamento do aglomerado de partículas.

Faroldi [48] se propõe a evitar problemas advindos da distância entre o dispositivo dosador de pó e a tocha em sua patente. Deste modo, ele é embutido no próprio corpo da tocha. Sua injeção ao arco se dá exclusivamente por efeito da gravidade. Estão excluídas, portanto, aplicações manuais e fora da posição plana.

A Figura 10 mostra o dispositivo que tem o princípio da válvula rotativa [49-51]. A rotação do tambor, junto à regulagem do gap entre o tambor e a face do canal de queda, determina a vazão de pó metálico que está armazenado em um silo pressurizado. Para cada pó dever ser realizada uma calibração, devido a diferentes propriedades de escoamento. Isto vale também para os outros tipos de ADP.

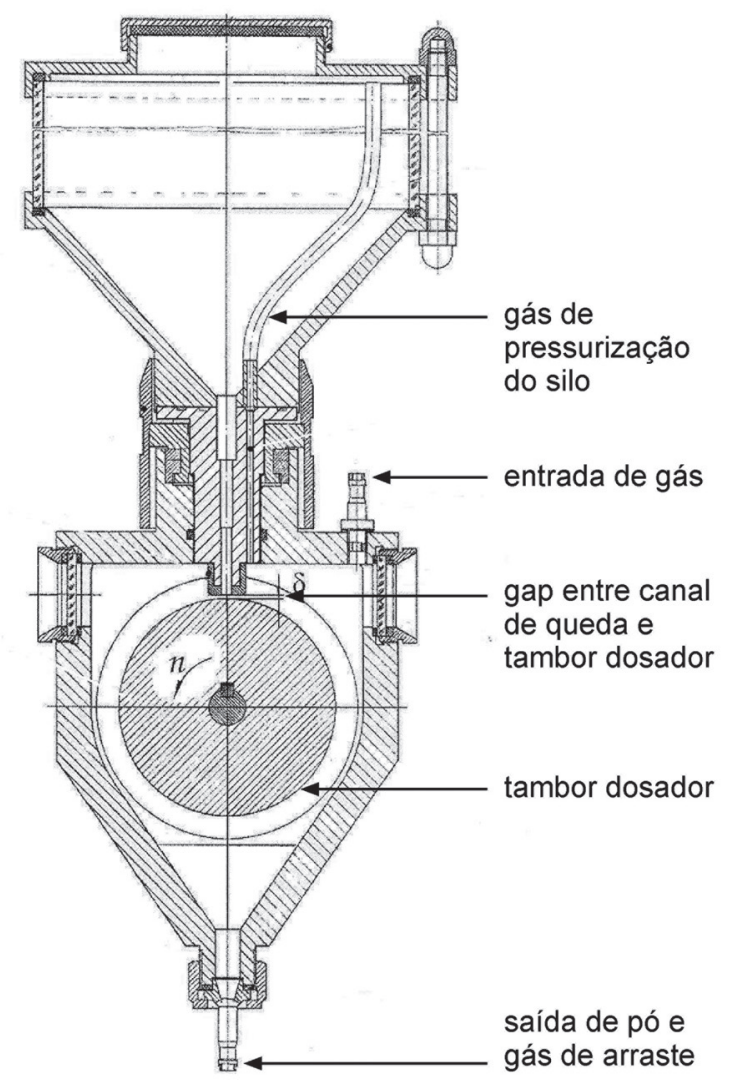

Figura 10. ADP do tipo válvula rotativa (adaptado de [50])

\section{Considerações Finais}

É possível concluir que, em se tratando do processo PTA-P, existem diversos aspectos a serem considerados em uma eventual tentativa para classificar e normatizar suas variações. A começar pela sua nomenclatura, culminando nas preconizadas vantagens e propriedades, que, na maioria das vezes, se baseiam ainda nas características do processo PAW, fornecendo, assim informações errôneas sobre o PTA-P. Mais importante do que a normatização / classificação é o fato de que, para o usuário, isso pode acarretar em falsas expectativas, dificuldades de implementação, desapontamento e até um descarte prematuro deste processo para suas aplicações industriais.

Às citadas dificuldades para interpretação de propriedades e aplicações do processo, soma-se a profusão de princípios e técnicas construtivas de tochas de soldagem e alimentadores de pó, cada qual com suas limitações, vantagens e aplicações. Normalmente, tais informações não são detalhadas em seus relatos, nem tecnologicamente, tampouco cientificamente. Não obstante, devido a sua capacidade de obter ótimo desempenho em determinadas aplicações, o processo é muito encontrado industrialmente, na Europa, e ainda deve ganhar espaço no Brasil.

O conhecimento mais aprofundado de todas as variações de componentes do sistema (tochas, ADPs, fontes) e das reais propriedades do PTA-P que o diferenciam do PAW, permitem uma adequada e sistemática análise e comparação de informações, de modo que as melhores práticas e opções tecnológicas sejam levadas em consideração quando de projetos de Pesquisa, Desenvolvimento e Inovação. No presente caso, o conhecimento adquirido da literatura, foi confrontado entre si e com resultados próprios obtidos no LABSOLDA - UFSC, de maneira crítica e criteriosa, propiciando embasamento para o projeto de um sistema integrado e compacto, com respectiva parametrização, para aplicação do Processo PTA-P em de ambientes de mobilidade limitada ou dificultada (p. ex. caldeiras de termelétricas, turbinas de hidrelétricas e pátios de estaleiros) sob condições não convencionais, como a soldagem fora da posição plana.

Em relação à tocha de soldagem, se nota que diferentes aplicações exigem diferentes conceitos de design. Aplicações manuais exigem tochas mais compactas, o que, por sua vez, exige melhor eficiência de refrigeração, para que se mantenha sua capacidade de corrente num ciclo de trabalho satisfatório. Tochas com injeção externa de pó são mais adequadas a aplicações fora da posição plana, devido a maior imunidade a entupimentos. Também as características morfológicas e químicas do pó de adição disponível influenciam o projeto da tocha.

Já a seleção ou projeto do Alimentador de Pó, ADP, foi constatado que o princípio de dosagem por fuso apresenta, sob condições ensaiadas, comprometimento de linearidade e repetitividade. Dentre as opções de princípios construtivos encontrados, o de válvula rotativa se mostra uma potencial solução, com vantagens também de simplicidade de projeto e operacionalidade em relação ao alimentador tipo mesa.

\section{Referências Bibliográficas}

[1] DEUIS, R. L. et al. Metal-matrix composite coatings by PTA surfacing. Composites Science and Technology, v.58, n. 2, p. 299-309, 1998

[2] MARCONI, M.; MARCONI, B. Powder Plasma Arc Welding on Thick Walled Pipes. International Institute of Welding, 16 p., Paper 11. 2005.

[3] FAUCHAIS, P.; VARDELlE, A. Thermal Plasmas. IEEE 
Transactions on Plasma Science, v.25, n.6, dez. 1997

[4] EST. DAIDO Steel. 6 p.

[5] PTA Welding Systems. ISOTEC, 24 p., set./2001.

[6] FÜSSEL, U. Lichtbogentechnologie zum Fügen - noch nicht ausgeschöpfte und nicht erkannte Potentiale. Artigo do DFK (Dresdner Fügetechnisches Kolloquium) 2006, 9 p.. Dresden, mar. 2006

[7] MARCONI, M. I Riporti duri con polveri saldate con il processo P.T.A. (Plasma ad Arco Trasferito). Livro Online (www.plasmateam.com), 320 p. 2002.

[8] RAGHU, D.; WEBBER, R. PTA Proves its Worth in HighVolume Hardfacing Jobs. Welding Journal, v. 75, n. 2, p. 34-40. Miami, fev. 1996

[9] KABATNIK, L. Plasma-Pulver-Schweißen Verschleißbeständiger Schichten auf Aluminiumwerkstoffe. 2002. 128 f. Tese (Doutorado em Engenharia) - RheinischWestfälisch Technisch Technisch Hochschule Aachen

[10] SUN, Z.; HUANG, Z.H. Micro-PTA powder cladding on a hot work tool steel. Int. J. of Materials and Product Technology, v.13, ns. 3-6, p. 146-154, 1998

[11] DOLLES, M. Untersuchungen zur Verfahrenskombination Laser-Plasma-Auftragschweißen. 2002. 160 f. Trabalho de Conclusão de Curso (Diplomarbeit) (Engenharia Mecânica) Fachhochschule Amberg-Weiden

[12] HONGYING, W. et al. Investigation on the deposition rate and the dilution ratio of plasma surface welding. China Welding, v.11, n.1, p.55-58, mai. 2002

[13] Arcraft Plasma website. Disponível em www.arcraftplasma. com. Acesso em mar. 2009

[14] DILTHEY, U.; KABATNIK, L. Zentrale Pulverzufuhr beim Plasma-Pulverauftragschweissen. Schweissen \& Schneiden, n. 12, p. 766-771. Düsseldorf, dez. 1998

[15] GEBERT, A. et al. Plasma-Pulver-Auftragschweissen. Oberflächentechnik, n.1, p. 56-60. München, 1996

[16]DRAUGELATES, U. et al. Surfacing with Combinations of Wire and Powder for Producing Hard Material-reinforced Wear Resistant Layers. Welding and Cutting, n. 4, p. 39-41. Düsseldorf, abr. 1995

[17] WAHL, W.; KRAUSKOPF, F. Plasma-arc Powder Surfacing of Ferrous Materials. Welding and Cutting, n. 2, p. 15-16. Düsseldorf, fev. 1993

[18] BEWLEY, J.G. Plasma-transferred-arc Wearfacing. Tooling \& Production, p. 54-55. dez. 1980

[19] SHUBERT, G. Wearsurfacing with PTA: Tips for the Firsttime User. Tooling \& Production, p. 60-61. nov. 1984

[20]XIBAO, W.; WENYUE, Z. The Theoretical Evaluation of Powders Transportation in Plasma Transferred-arc Space under Coaxial Powder Feeding Condition. China Welding, v.10, n.2, p. 104-110. nov. 2001

[21]XIBAO, W.; HUA, L. Metal Powder Thermal Behavior during the Plasma Transferred-arc Surfacing Process. Surface and Coatings Technology, v. 106, n. 1-2, p. 156-161. ago.1998 [22] DÍAZ, V. M. V., Inovação do Equipamento e Avaliação do Processo Plasma de Arco Transferido Alimentado com Pó (PTAP) para Soldagem Fora de Posição. 2005, 198 f. Tese (Doutorado em Engenharia) - Universidade Federal de Santa Catarina, Florianópolis
[23] TETSU, I., et al. Plasma powder welding device and its welding method. Patente n. US2004159640.

[24] SOM, A. I. New Plasma Torches for PTA-surfacing. Artigo disponível em www.plasma-master.com.ua. Acesso em fev. 2006

[25]RIBEIRO, H. O. Desenvolvimento de Ligas para Revestimentos por PTA Resistentes à Cavitação. 2007. 167 f. Tese (Doutorado em Engenharia) - Universidade Federal de Santa Catarina

[26] STELLING， K. Laserstrahl-Plasma-Hybridschweißen Austenitischer Stähle. 2008. 135 f. Tese (Doutorado em Engenharia) - Universidade Técnica de Berlin

[27]DESIR, J.L. Plasma Arc Coatings Combat Component Wear. Welding and Metal Fabrication, p. 219-222. jun. 1983

[28] HALLEN, H. et al. Plasma Transferred Arc Surfacing with High Deposition Rates. Proceedings of the $4^{\text {th }}$ National Thermal Spray Conference. p. 537-539. Pittsburg, mai. 1991

[29] TUR, M. Method for Plasma Transferred Arc Welding. Depósito de patente n. 8903522.4. UK Patent Office, ago. 1990 [30] WHITE, R. A., et al. Underwater Welding with Laser and Plasma Arc Welding. Welding Journal, v. 76, n. 1, p. 57-61. Miami, jan. 1997

[31] WHITE , R. A.; SOLOMON, H. D. Water Exclusion Device for Underwater Welding. Patente n. 5,750,954. USPTO. 12/05/1998

[32]DRAUGELATES, U.; BOUAIFI, B.; SCHULTZE, S. Hochleistungs-Plasmapulverauftragschweißen mit Duplexstählen. Schweissen \& Schneiden, n. 5, p. 245-251. Düsseldorf, mai. 1999

[33] New Generation of Plasma Welding Torches. Informação de Imprensa da TBi. Welding and Cutting, n. 3, p. 130-131. Düsseldorf, mar. 2007

[34] PAVLENKO, A. Neue Kentnisse über Phylikalische Grundlagen des Plasma-Pulver-Auftragschweißens als Basis für die Prozeßsteuerung. 1996. 118 f. Tese (Doutorado em Engenharia) - Rheinisch-Westfälisch Technisch Technisch Hochschule Aachen

[35] SIDOROV, A.I. Altering the Design of the Anode of a Plasma Torch to Increase the Efficiency of Deposition (to Reduce Gas Consumption). Svar. Proiz., n.6, p. 17-18. 1978 [36] BOELLINGHAUS, T.; SCHOBBERT, H. Nd: YAG Laser Plasma Powder Hybrid Welding of Austenitic Stainless Steels. $6^{\text {th }}$ International Trends in Welding Research Conference Proceedings. p. 453-458. Pine Mountain, 2003

[37] SCHNICK, M. et al. Simulation von Plasmalichtbögen. Artigo do DFK 2006, 10 p.. Dresden, mar. 2006

[38]SCHNICK, M. et al. Der Lichtbogen in der Prozesssimulation-die realen Möglichkeiten zum Beispiel für die Brennerentwicklung. Apresentação em Seminário no SLV München. 33 p.. Munique, 27/03/2007

[39] GOMIDE, R., Operações Unitárias, v.1 Operações com Sistemas Sólidos Granulares, $1^{\text {a }}$ edição. Ed. do Autor. 1980 [40]HUANG, X. et al. Applications of PTA Powder Welding in Petroleum Chemical Industry. Proceedings of the $15^{\text {th }}$ International Thermal Spray Conference, p. 1013-1017. Nice, mai. 1998

[41] MILLIGAN, J.; NARASIMHAN, S. A Powder Fed Plasma 
Transferred Arc Process for Hard Facing Internal Combustion Engine Valve Seats. SAE Technical Paper Series, Congress and Exposition Cobo Hall, 12 p. Detroit, fev. 1980

[42] GLYNN, T. Plasma Transferred Arc and HVOF Hardfacing Processes. Apresentacao à AWS. 2007

[43] STEEN, W. et al. Screw Powder Feeders. Depósito de Patente n. PCT/GB85/00456. European Patent Office, 11/10/1985

[44] STAND, M., STREICHER,A.H.Pulverzufördervorrichtung. Depósito de Patente n. 2144871. Deutsches Patentamt. $15 / 03 / 1973$

[45]BOHORQUEZ, C. E. N. Relatório de Ensaios da Taxa de Alimentação de Pó. Relatório Interno LABSOLDA, 8 p.. Florianópolis, 26/06/2008

[46] SPIVANOVSKY, A. et al. Conveyors and Related Equipment. Peace Publishers. 444 p. Moscou, 1970

[47] UCHIDA, K.; OKAMOTO, K. Measurement of Powder Flow in a Screw Feeder by X-ray Penetration Image Analysis. Measurement Science and Technology, v.17, n. 2, p. 419-426. fev. 2006

[48] FAROLDI, B. Device for Plasma Welding Having a Powder Dosing Member Acting by Gravity Fall. Depósito de Patente $n$. PCT/EP96/01707. European Patent Office, 23/04/1996

[49] Drum Feeder for Introducing Powder into a Plasma Jet. Patente n. SU266111-A. ISI Web of Knowledge

[50] PM- PF-10 Operating Manual. Plasma Master. 6 p.

[51] VSEVOLODOV, B. A.; SEMENOV, S. A.; MILBUD, S. R. Powder Feeder - has Body Equipped with Sleeve Having Inclined Axial Opening and Groove on Cylindrical Surface. Patente n. SU1493417-A. ISI Web of Knowledge. 15/7/1989 